\title{
Synthesis of Lithium-Manganese Orthosilicate and its Application as Cathode Material in Lithium-Ion Batteries
}

\author{
Maciej Boczar ${ }^{1}$, Michal Krajewski ${ }^{1}$, Maciej Ratynski ${ }^{1}$, Bartosz Hamankiewicz, ${ }^{1,2}$ and \\ Andrzej Czerwinski, \\ ${ }^{1}$ Faculty of Chemistry, University of Warsaw, Pasteura 1, 02-093 Warsaw, Poland \\ ${ }^{2}$ Biological and Chemical Research Centre, University of Warsaw, Zwirki i Wigury 101, 02-089 \\ Warsaw, Poland \\ ${ }^{3}$ Industrial Chemistry Research Institute, Rydygiera 8, 01-793 Warsaw, Poland \\ *E-mail: bhamankiewicz@ chem.uw.edu.pl, aczerw@ chem.uw.edu.pl
}

doi: $10.20964 / 2018.12 .27$

Received: 5 April 2018 / Accepted: 4 July 2018 / Published: 5 November 2018

Lithium-manganese orthosilicate powders were synthesized by a modified sol-gel method. The LMS powders were carbon coated by two different methods. The conductive cathode layer has been obtained by carbonization of organic precursor either on the grains of previously synthesized lithiummanganese orthosilicate or reduction of carbon source during active material synthesis (internal coating). Synthesized materials were analyzed by XRD, SEM, $\mathrm{N}_{2}$ adsorption/desorption and electrochemical $\mathrm{CP}$ and $\mathrm{CV}$ methods. The internal coating approach improved the electrochemical performance of $\mathrm{Li}_{2} \mathrm{MnSiO}_{4}$ powder, increasing its specific capacity and cyclability by enhancing its electrical conductivity and enlarging its electrochemically active surface area.

Keywords: Li2MnSiO4, li-ion battery, sol-gel synthesis, carbon coating, lithium-manganese orthosilicate

\section{FULL TEXT}

(C) 2018 The Authors. Published by ESG (www.electrochemsci.org). This article is an open access article distributed under the terms and conditions of the Creative Commons Attribution license (http://creativecommons.org/licenses/by/4.0/). 